\title{
Metabolic syndrome and renal sodium handling in three ethnic groups living in England
}

\author{
A. Barbato ${ }^{1}$, F. P. Cappuccio ${ }^{1}$, E. J. Folkerd ${ }^{1}$, P. Strazzullo², B. Sampson ${ }^{3}$, D. G. Cook ${ }^{1}$, K. G. M. M. Alberti ${ }^{4}$ \\ ${ }^{1}$ Department of Community Health Sciences, St George's Hospital Medical School, London, UK \\ 2 Department of Clinical and Experimental Medicine, Federico II Medical School, University of Naples, Italy \\ 3 Trace Element Laboratory, Department of Clinical Chemistry, Imperial College School of Medicine at Charing Cross, London, UK \\ ${ }^{4}$ Department of Medicine, University of Newcastle-upon-Tyne, UK
}

\section{Abstract}

Aim/hypothesis. Increased proximal renal sodium reabsorption is associated with central adiposity and insulin resistance in white men. Our study examined whether this association also exists in other ethnic groups with different prevalences of insulin resistance and associated metabolic abnormalities.

Methods. We studied the association between fractional renal excretion of endogenous lithium (FELi) and metabolic syndrome in a population study of 1190 randomly selected men and women who where 40 to 59 years of age (426 white, 397 of African and 367 of South Asian origin). Anthropometric values, blood pressure, biochemical values, questionnaire data and timed urine collections were obtained with standardised techniques. Endogenous lithium in serum and urine was measured by absorption spectrophotometry. Metabolic markers were the homeostasis model assessment (HOMA) index, waist circumference, serum triglycerides, serum HDL cholesterol and metabolic syndrome as defined by Adult Treatment Panel III criteria.
Results. In white men and women a higher rate of proximal sodium re-absorption was inversely associated with higher waist circumference, serum triglycerides and HOMA index, and with lower serum HDL cholesterol (all $p \leq 0.001$ ). No associations were found in people of African or South Asian origin. The former had lower FELi than the other groups. White people with the metabolic syndrome had a lower FELi than those without $(15.9 \%$ vs $19.0 \% ; p=0.003)$. No difference was found in people of African or South Asian origin.

Conclusions/interpretation. Increased proximal sodium re-absorption is associated with the metabolic syndrome in white men and women. This relationship is not seen in people of African or South Asian origin, despite a greater degree of insulin resistance. [Diabetologia (2004) 47:40-46]

Keywords Fractional renal excretion of lithium - renal sodium re-absorption - metabolic syndrome · ethnic groups $\cdot$ Adult Treatment Panel III
Received: 10 July 2003 / Revised: 3 September 2003

Published online: 15 November 2003

C) Springer-Verlag 2003

Prof. F. P. Cappuccio ( $\bullet$ ), Department of Community Health Sciences, St George's Hospital Medical School, Cranmer Terrace, London, SW17 ORE UK

E-mail: f.cappuccio@sghms.ac.uk

Abbreviations: FELi, fractional renal excretion of endogenous lithium; HOMA, homeostasis model assessment; FENa, fractional excretion of sodium; cAMP, cyclic adenosine monophosphate.

Electronic Supplementary Material

Supplementary material is available in the online version of this article at http://dx.doi.org/10.1007/s00125-003-1260-z
In untreated white men $[1,2]$ increased proximal renal sodium re-absorption, measured as clearances of lithium and uric acid, is consistently and independently associated with a metabolic pattern of insulin resistance, suggesting that renal sodium handling is involved in the "metabolic syndrome". Recently an association has also been reported between abdominal adiposity and altered renal tubular sodium handling in white men [3]. However, it is not clear if the relationship between altered sodium handling, abdominal adiposity and insulin resistance is present in women too or whether it exists in other ethnic groups (e.g. people of African or South Asian origin), which have differ- 
ent prevalences of insulin resistance, distribution of adiposity and cardiovascular risk [4, 5].

We therefore assessed whether (i) the association between greater proximal sodium retention and metabolic syndrome is present in white women as well as in white men; (ii) the renal handling of sodium differs among ethnic groups known to have different vascular morbidity and mortality rates; and (iii) differences in handling of sodium are related to the metabolic syndrome within each ethnic group.

\section{Subjects and methods}

Population sampling. The methodology and overall characteristics of the study population of the Wandsworth Heart and Stroke Study have been reported in detail elsewhere [4, 6]. In brief, men and women 40 to 59 years of age were recruited from the lists of general practices in South London between March 1994 and July 1996. The ethnic group was recorded during an interview based on answers to questions on factors including place of birth, language, religion, history of migration and parental country of birth. The final sample size was 1577 . Of these 1257 (80\%) provided timed urine collections for clearance studies. A complete data set for analysis was available for 1190 subjects (426 white, 397 of African and 367 of South Asian origin). All participants from ethnic minority groups were first-generation immigrants. The general characteristics of people included in the analysis did not differ from those of people excluded (Appendix Table I online). The study was approved by the Local Ethics Committee. All participants gave their informed consent and the study was carried out in accordance with the Declaration of Helsinki as revised in 2000.

Methods. Participants were seen between 08.00 hours and 12.00 hours after an overnight fast. They received written instructions to empty their bladder in the morning, record the time and drink one to two glasses of tap water before attending the screening. They were asked not to smoke or to exercise vigorously for at least one hour before the visit, and to bring all medications they were taking for checking. The examination included anthropometry, blood pressure, a fasting timed urine collection and a detailed questionnaire. Age at the last birthday was recorded. Height, weight, waist and hip girths were measured with standard methods $[4,6]$ and BMI was calculated $\left(\mathrm{kg} / \mathrm{m}^{2}\right)$. Blood pressure was measured after the subject had been resting for at least $10 \mathrm{~min}$ in the supine position with an automatic ultrasound sphygmomanometer as described elsewhere $[4,6]$. A fasting timed urine collection was obtained on the morning of the investigation. The volume $(\mathrm{ml})$ and duration ( $\mathrm{min}$ ) of the collection were recorded and specimens were aliquoted and stored at $-20^{\circ} \mathrm{C}$. Fasting venous blood was taken in the seated position without stasis. Serum electrolytes, creatinine, glucose and lipids were measured as described $[4,6]$. Serum insulin was measured by a two-site ELISA, using monoclonal antibodies (Novo Nordisk A/S; Denmark) raised against human insulin and which do not cross-react with pro-insulin [6]. Insulin resistance was estimated by homeostasis model assessment (HOMA) using the formula: fasting serum insulin $(\mu \mathrm{U} / \mathrm{ml}) \times$ fasting serum glucose $(\mathrm{mmol} / \mathrm{l}) / 22.5$ [7]. The metabolic syndrome was defined according to Adult Treatment Panel III criteria [8].

Questionnaire. This consisted of 134 items, including questions on demographic and socio-economic information such as place of birth, language, religion, history of migration, parental place and country of birth, family history, marital status, social class and education of the screened person and his or her spouse or partner (when indicated), as well as housing. It also contained questions on personal medical history and drug therapy, current and past smoking, and leisure-time physical activity during the preceding 2 weeks.

Endogenous lithium clearance. After the physical measurements participants completed a timed urine collection, having fasted from the night before. On the morning of the examination they refrained from smoking, strenuous physical exercise and drinking tea, coffee and other drinks containing caffeine. Urine samples were stored at $-20^{\circ} \mathrm{C}$ until assayed for sodium, lithium and creatinine concentrations. The clearances of sodium, lithium and creatinine were calculated by standard formulae [9]. Fractional excretion of sodium (FENa) and lithium (FELi) were also calculated [9]. FELi was used in the analysis to minimise the confounding effect of age, anthropometric factors and body mass [10]. Endogenous lithium was measured by absorption spectrophotometry (electrothermal method; AAS, model 3030; Perkin Elmer, Seer Green, Bucks, UK) [11, 12]. The detection limit for lithium in serum is $0.05 \mu \mathrm{mol} / \mathrm{l}$. The between-batch CV for serum was $10.8 \%(n=100)$ and the withinbatch CV $6.2 \%(n=23)$. For urine, the between-batch CV was $6.2 \%(n=185)$ and the within-batch CV $4.6 \%(n=27)$.

Statistical analysis. Statistical analysis was done using the Statistical Package for Social Sciences (SPSS-PC; SPSS, Chicago, Ill., USA). The distributions of serum triglycerides, HDL cholesterol, fasting insulin and HOMA index were normalised by log-transformation, and the log-transformed values used in the analyses. Results are expressed as means or geometric means with and $95 \%$ confidence intervals as indicated. Due to differences in age and sex all statistical analyses were carried out after adjustment for age and sex. Partial correlation analyses were used to test associations between different variables, controlling for age and sex. Analysis of co-variance was used to adjust for confounders. The following were considered to be confounders: (i) variables associated with the FELi and any of the metabolic variables under study; (ii) variables that have previously been reported to be associated with both of the former. However, as insulin resistance could be the explanatory link, we did not think it appropriate to adjust for some of the variables, which could be interrelated because they are on the common metabolic pathway. Multiple linear regression analysis was used to allow for confounders using FELi as dependent variable. The prevalence of drug treatments in subjects with and without metabolic syndrome was tested by chi square. A two-sided $p$ value of less than 0.05 was considered statistically significant.

\section{Results}

Descriptive statistics. Table 1 summarises the main differences between groups, adjusted for age and sex. HOMA index, serum glucose and insulin concentrations were progressively higher in people of African and South Asian origin than in white subjects. There were also more hypertensive subjects and people with diabetes in ethnic minority groups than in the white group. The average urine collection time was not different in the three groups but average urine volume was lower in people of African origin (Table 1). In people of African origin FELi and FENa were both 
Table 1. Age- and sex-adjusted characteristics by ethnic group

\begin{tabular}{|c|c|c|c|c|c|c|c|}
\hline & \multicolumn{2}{|l|}{$\begin{array}{l}\text { White } \\
n=426\end{array}$} & \multicolumn{2}{|c|}{$\begin{array}{l}\text { African origin } \\
n=397\end{array}$} & \multicolumn{2}{|c|}{$\begin{array}{l}\text { South Asian } \\
n=367\end{array}$} & \multirow[t]{2}{*}{$p$} \\
\hline & Mean & $95 \% \mathrm{CI}$ & Mean & $95 \% \mathrm{CI}$ & Mean & $95 \% \mathrm{CI}$ & \\
\hline Systolic BP (mmHg) & 125.2 & 123.5 to 126.9 & 133.5 & 131.6 to 135.5 & 128.7 & 126.8 to 130.6 & $<0.001$ \\
\hline Diastolic BP (mmHg) & 79.5 & 78.9 to 80.4 & 86.2 & 85.2 to 87.3 & 82.7 & 81.7 to 83.8 & $<0.001$ \\
\hline BMI $\left(\mathrm{kg} / \mathrm{m}^{2}\right)$ & 25.9 & 25.5 to 26.4 & 27.9 & 27.4 to 28.3 & 25.9 & 25.5 to 26.4 & $<0.001$ \\
\hline Waist-to-hip ratio & 0.861 & 0.854 to 0.867 & 0.876 & 0.868 to 0.883 & 0.895 & 0.887 to 0.903 & $<0.001$ \\
\hline Total cholesterol (mmol/l) & 6.21 & 6.12 to 6.32 & 5.61 & 5.49 to 5.72 & 5.71 & 5.60 to 5.82 & $<0.001$ \\
\hline HDL cholesterol $(\mathrm{mmol} / \mathrm{l})^{\delta}$ & 1.34 & 1.30 to 1.37 & 1.45 & 1.38 to 1.46 & 1.15 & 1.12 to 1.18 & $<0.001$ \\
\hline Serum triglycerides $(\mathrm{mmol} / \mathrm{l})^{\delta}$ & 1.21 & 1.16 to 1.27 & 0.82 & 0.79 to 0.85 & 1.38 & 1.31 to 1.45 & $<0.001$ \\
\hline Serum insulin $(\mathrm{pmol} / \mathrm{l})^{\delta}$ & 6.84 & 6.46 to 7.26 & 8.18 & 7.66 to 8.74 & 10.70 & 10.02 to 11.40 & $<0.001$ \\
\hline Serum glucose (mmol/l) & 5.13 & 5.02 to 5.24 & 5.43 & 5.25 to 5.62 & 5.64 & 5.46 to 5.83 & $<0.001$ \\
\hline Lipid-lowering treatment $*$ & $3(0.7)$ & & $3(0.8)$ & & $4(1.1)$ & & 0.825 \\
\hline Oral antidiabetic treatment $*$ & $3(0.7)$ & & $18(4.5)$ & & $12(3.2)$ & & 0.003 \\
\hline Timed urine collections & Mean & $95 \% \mathrm{CI}$ & Mean & $95 \% \mathrm{CI}$ & Mean & $95 \% \mathrm{CI}$ & \\
\hline Time (min) & 151 & 146 to 156 & 157 & 151 to 162 & 152 & 146 to 158 & 0.288 \\
\hline Volume (ml) & 294 & 275 to 313 & 238 & 220 to 256 & 273 & 255 to 292 & $<0.001$ \\
\hline Creatinine clearance $(\mathrm{ml} / \mathrm{min})$ & 91.9 & 89.2 to 94.7 & 94.8 & 91.6 to 98.1 & 76.5 & 73.6 to 79.5 & $<0.001$ \\
\hline FE of sodium $(\%)$ & 0.81 & 0.78 to 0.85 & 0.79 & 0.75 to 0.83 & 0.99 & 0.93 to 1.04 & $<0.001$ \\
\hline FE of lithium (\%) & 18.4 & 17.6 to 19.1 & 15.6 & 15.0 to 16.3 & 18.2 & 17.4 to 18.9 & $<0.001$ \\
\hline
\end{tabular}

* Individuals possibly on more than one treatment (45 in white, 134 in African, 64 in South Asian group). ${ }^{\delta}$ Geometric means. FE, fractional excretion

lower than in the other groups (Table 1). Values for FENa were higher in South Asian subjects, possibly indicating a higher dietary sodium intake. All these differences between groups were not due to differences in the proportion of people treated for hypertension, hyperlipidaemia or diabetes (Appendix Table II online).

FELi and indices of insulin resistance. In white subjects FELi was consistently and inversely associated with BMI, waist and hip circumference, waist-to-hip ratio, serum triglycerides, fasting glucose, insulin and HOMA index, and directly associated with HDL cholesterol, indicating that an enhanced rate of proximal sodium re-absorption is associated with a greater degree of insulin resistance (Table 2). However, no such pattern was detected amongst people of African or South Asian origin. Age-adjusted regression models by sex indicated [with the exception of waist circumference (interaction $p=0.032$ )] that the associations were similar in the two sexes. This also applied after the exclusion of treated individuals (Appendix Table III online ). Multiple linear regression models, adjusted for age and sex, confirmed that the relationships were confined to white subjects and were consistent with HOMA index, waist circumference, serum triglycerides and HDL cholesterol, with significant interaction tests
Table 2. Fractional excretion of lithium vs metabolic variables: age- and sex-adjusted partial correlation coefficients by ethnic group, including subjects on treatment

\begin{tabular}{|c|c|c|c|}
\hline Variable & $\begin{array}{l}\text { White } \\
(n=426)\end{array}$ & $\begin{array}{l}\text { African } \\
\text { origin } \\
(n=397)\end{array}$ & $\begin{array}{l}\text { South } \\
\text { Asian } \\
(n=367)\end{array}$ \\
\hline ystolic BP (n & .01 & -0.0 & 0.0 \\
\hline iastolic BP ( $\mathrm{r}$ & 0.02 & -0.0 & 0.0105 \\
\hline $\operatorname{BMI}\left(\mathrm{kg} / \mathrm{m}^{2}\right)$ & $-0.1590 *$ & -0.0371 & 0.0099 \\
\hline Waist (cm) & $-0.1479 *$ & -0.0402 & 0.0016 \\
\hline Hip (cm) & -0.1 & -0 . & 0.0077 \\
\hline Waist-to-hip ratio & $-0.1054^{*}$ & -0.0316 & 0.0017 \\
\hline Total cholesterol (mr & -0.0009 & 0.0673 & -0.0122 \\
\hline HDL cholesterol $(\mathrm{mmol} / \mathrm{l})^{\delta}$ & $0.0987 *$ & -0.0079 & -0.0359 \\
\hline Serum triglycerides $(\mathrm{mmol} / \mathrm{l})^{\delta}$ & $-0.1260 *$ & -0.0 & -0.0419 \\
\hline Serum insulin $(\mathrm{pmol} / \mathrm{l})^{\delta}$ & $-0.0873 * *$ & -0.0792 & 0.0020 \\
\hline$(\mathrm{mmol} / \mathrm{l})$ & $-0.1209 *$ & 0.0044 & 0.0510 \\
\hline HOMA index $^{\delta}$ & $-0.1097 *$ & -0.0730 & 0.0117 \\
\hline
\end{tabular}

$\delta$ Log-transformed for analysis; $* p=0.001 ; * * p=0.072$

for waist circumference $(p=0.019)$ and HDL cholesterol $(p=0.027$, Table 3$)$. The $r^{2}$ values were 0.040, 0.049, 0.043 and 0.037 respectively, indicating that approximately 4 to $5 \%$ of the variance in FELi was explained by those simple models. The exclusion of subjects taking medication did not substantially alter the pattern of 
Table 3. Age- and sex-adjusted multiple regression analyses by ethnic group in the whole population (dependent variable: FE of lithium)

\begin{tabular}{|c|c|c|c|c|c|c|c|c|c|}
\hline Ethnic group & $n$ & $\begin{array}{l}\text { Log HOMA } \\
\text { (units/FELi) } \\
\beta(95 \% \mathrm{CI})\end{array}$ & $p$ & $\begin{array}{l}\text { Waist } \\
(\mathrm{cm} / \mathrm{FELi}) \\
\beta(95 \% \mathrm{CI})\end{array}$ & $p$ & $\begin{array}{l}\text { Log } \\
\text { triglycerides } \\
\text { (mmol/l per } \\
\text { FELi) } \\
\beta(95 \% \mathrm{CI})\end{array}$ & $p$ & $\begin{array}{l}\text { Log HDL-Chol } \\
(\mathrm{mmol} / \mathrm{l} \text { per } \\
\text { FELi) } \\
\beta(95 \% \mathrm{CI})\end{array}$ & $p$ \\
\hline White & 426 & $\begin{array}{l}-1.247 \\
(-2.329 \text { to } \\
-0.166)\end{array}$ & 0.024 & $\begin{array}{l}-0.101 \\
(-0.166 \text { to } \\
-0.036)\end{array}$ & 0.002 & $\begin{array}{l}-1.914 \\
(-3.355 \text { to } \\
-0.472)\end{array}$ & 0.009 & $\begin{array}{l}2.7(0.073 \text { to } \\
5.465)\end{array}$ & 0.044 \\
\hline African origin & 397 & $\begin{array}{l}-0.667 \\
(-1.570 \text { to } \\
0.236)\end{array}$ & 0.147 & $\begin{array}{l}-0.023 \\
(-0.081 \text { to } \\
0.034)\end{array}$ & 0.425 & $\begin{array}{l}-0.643 \\
(-2.275 \text { to } \\
0.989)\end{array}$ & 0.439 & $\begin{array}{l}-0.192 \\
(-2.595 \text { to } \\
2.211)\end{array}$ & 0.875 \\
\hline South Asian & 367 & $\begin{array}{l}0.128 \\
(-0.989 \text { to } \\
1.244)\end{array}$ & 0.822 & $\begin{array}{l}0.001 \\
(-0.071 \text { to } \\
0.074)\end{array}$ & 0.975 & $\begin{array}{l}-0.674 \\
(-2.324 \text { to } \\
0.976)\end{array}$ & 0.422 & $\begin{array}{l}-1.094 \\
(-4.216 \text { to } \\
2.028)\end{array}$ & 0.491 \\
\hline
\end{tabular}

$r^{2}$ in white group: Log HOMA $=0.040$; waist $=0.049 ; \log$ triglycerides $=0.043 ; \log$ HDL cholesterol $=0.037$

FE, fractional excretion; FELi, fractional renal excretion of endogenous lithium; HOMA, homeostasis model assessment

Table 4. Fractional excretion of lithium: age- and sex-adjusted differences between participants with and without metabolic syndrome according to Adult Treatment Panel III criteria

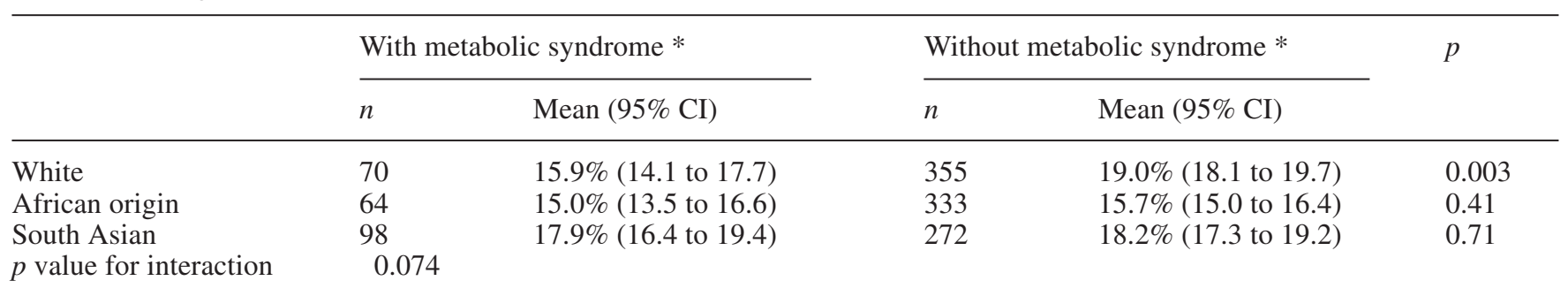

* Adult Treatment Panel III criteria: three or more of the following criteria: waist circumference (men $>102 \mathrm{~cm}$, women $>88 \mathrm{~cm}$ ), triglycerides $\geq 1.7 \mathrm{mmol} / \mathrm{l}$, HDL cholesterol (men

associations and interactions (Appendix Table IV online). Likewise, the $r^{2}$ values did not change substantially (0.041, 0.055, 0.044 and 0.043 respectively). Further models adjusted for systolic blood pressure, degree of physical activity and smoking produced similar results (Appendix Table $\mathrm{V}$ online). The $r^{2}$ values increased to $0.056,0.069,0.058$ and 0.051 respectively.

FELi and the metabolic syndrome. To further quantify the difference in renal tubular proximal sodium handling in patients with and without the metabolic syndrome, we used the Adult Treatment Panel III criteria. The method identified the metabolic syndrome in 70 white people, 64 people of African origin and 98 of South Asian origin. White subjects with the metabolic syndrome had lower FELi than those without it, when adjusting for age and sex (Table 4), and also when further allowance was made for differences in the proportion of people treated for hypertension, hyperlipidaemia or diabetes (Appendix Table VI online). No difference was seen in the other ethnic groups.
$<1.04 \mathrm{mmol} / \mathrm{l}$, women $<1.30 \mathrm{mmol} / \mathrm{l})$, blood pressure $\geq 130 / 85 \mathrm{mmHg}$, fasting glucose $\geq 6.11 \mathrm{mmol} / \mathrm{l}$

\section{Discussion}

In this study we found different degrees of association between components of the metabolic syndrome and FELi depending on ethnicity. We confirmed that lower FELi, i.e. a higher rate of proximal renal tubule sodium re-absorption, is associated with features of the metabolic syndrome in white people of both sexes, independently of major confounders such as smoking, drug therapy and degree of physical exercise. However, in people of African or South Asian origin these relationships were less clear or not present. We also found that: (i) the association originally described in white men $[1,2]$ existed in a different white population consisting of both sexes; (ii) the association is not present in people of African origin, who have more insulin resistance and central adiposity, or in South Asian subjects, who also have more insulin resistance and central adiposity, as well as higher serum triglycerides and lower HDL cholesterol; (iii) people of African origin have greater proximal sodium re-absorption 
than other ethnic groups; (iv) white people with the metabolic syndrome, in contrast to people of other ethnic backgrounds, have a lower FELi. Multivariate analyses indicate that the metabolic variables could explain approximately 4 to $5 \%$ of the variance in FELi. Whilst it may seem a small amount, this degree of sodium retention sustained over a long period of time could make a physiologically important contribution to total blood volume expansion and the activation of compensatory mechanisms.

We used the term metabolic syndrome to describe a cluster of abnormalities such as hyperinsulinaemia, glucose intolerance, hypertension, high triglyceride concentrations, low concentrations of HDL cholesterol and obesity, particularly central adiposity [13]. Reduced tissue responsiveness to the normal action of insulin (insulin resistance) is the underlying feature of the syndrome [14]. Insulin resistance and hyperinsulinaemia are commonly associated with central adiposity $[15,16]$. Although the hyperinsulinaemic euglycaemic insulin clamp is the gold standard for assessing insulin resistance, it is obviously unsuitable for large population studies. The HOMA index [7] gives only an indirect estimate of insulin-dependent glucose utilisation but it has been validated against the euglycaemic hyperinsulinaemic clamp [17]. Waist circumference predicts subsequent coronary artery disease better than BMI [18] and is recommended as a measure of abdominal adiposity $[8,19]$.

We used the urinary excretion rate of endogenous lithium as a validated non-invasive method to assess segmental renal tubular sodium and water handling [12]. A reduction in FELi suggests an increased rate of sodium and water re-absorption at the proximal tubule. The measurement of endogenous lithium is more accurate and reliable than that of exogenous lithium, which was often used in previous epidemiological investigations $[1,2,3,10]$.

Several mechanisms could explain the enhanced rate of renal tubular sodium re-absorption observed in white men and women in relation to the metabolic syndrome. In humans, insulin has an acute antinatriuretic effect [20], even in obese persons resistant to other metabolic effects of the hormone [21]. Although insulin is thought primarily to affect distal tubular sodium re-absorption [21, 22, 23, 24], there is evidence of a direct insulin action on proximal tubular sodium re-absorption [25, 26]; moreover, insulin receptors have been found in the proximal tubule of different species [27, 28, 29]. Finally, insulin increases the expression and the activity of sodium-hydrogen exchange isoform 3 , which mediates more than $60 \%$ of the sodium re-absorption at the proximal tubule [30].

Chronic hyperinsulinaemia associated with insulin resistance might reduce glucagon-stimulated production of hepatic cyclic adenosine monophosphate (cAMP) and, in turn, impair the recognised natriuretic influence of systemic cAMP on the proximal tubule
$[31,32]$. Activation of the sympathetic nervous system, which is associated with abdominal adiposity and hyperinsulinaemia, could modulate renal tubular sodium handling $[33,34,35]$.

Hyperglycaemia in vitro favours antinatriuresis due to enhanced glucose-sodium co-transport in the convoluted proximal tubule [25]. In vivo proximal sodium re-absorption is stimulated by hyperglycaemia in rats [36], and is higher in patients with diabetes [37]. Moreover, patients with Type 2 diabetes and insulin resistance retain more sodium than subjects without diabetes at similar plasma glucose concentrations and filtered glucose. At comparable degrees of hyperglycaemia, patients with greater insulin resistance have more sodium retention, suggesting that insulin resistance reflects an intrinsic renal abnormality [38] at least in white people. Our results are consistent with these views.

Our study raises an important question. If circulating concentrations of insulin and glucose explain the increased proximal tubular renal sodium handling in white people, why is a similar pattern not found in the other two groups, whose average serum insulin and glucose concentrations were even higher? The explanation for this difference is not at hand. An increase in dietary salt decreases insulin receptor number and mRNA levels in the kidney of normal Wistar-Kyoto and Sprague-Dawley rats [39]. However, when fructose is added to the high-salt diet and the rats become insulin-resistant and hypertensive, the salt-mediated decrease in insulin receptors is lost [39]. We do not know whether a similar interplay between differences in habitual sodium intake, susceptibility to hyperinsulinaemia and insulin resistance and prevalence of overt diabetes mellitus contributes to the different results observed in the various ethnic groups.

Finally, it cannot be ruled out that differences in genetic background play a role in the relationship between proximal renal sodium handling and indices of the metabolic syndrome. Several genetic mutations and a variety of gene polymorphisms have been related to alterations in the renal handling of sodium. Substantial interethnic differences have been shown in several cases [40, 41, 42]. Some of these genetic variants could also be involved in the salt-sensitivity of black African subjects with low-renin volume expanded hypertension [43]. Lower FELi, which reflects greater proximal sodium re-absorption, could be consistent with this hypothesis.

Acknowledgements. The Wandsworth Heart and Stroke Study received support from the Wandsworth Health Authority, the South West Thames Regional Health Authority, the National Health Service R\&D Directorate, the British Heart Foundation, the British Diabetic Association and The Stroke Association. A. Barbato holds a Salvatore Campus Fellowship of the Italian Society of Hypertension. We thank everyone who has been part of the Study Group over the years, including G.A. Sagnella, M.J. Rothwell, R.W. Atkinson, P.D. Wicks, S.M. Kerry, M.A. 
Miller, L. Ashworth, R. Iacone, C. Chazot, S. Choudhary, J. Cox and D. Powell, as well as the general practitioners and participants. F.P. Cappuccio and D.G. Cook. are members of the St George's Cardiovascular Research Group. The study was carried out in the framework of the IMMIDIET Project (QLK1CT-2000-00100 of the European Union).

\section{References}

1. Cappuccio FP, Strazzullo P, Siani A, Trevisan M (1996) Increased proximal sodium reabsorption is associated with increased cardiovascular risk in men. J Hypertens 14:909914

2. Cappuccio FP, Strazzullo P, Farinaro E, Trevisan M (1993) Uric acid metabolism and tubular sodium handling. Results from a population-based study. JAMA 270:354-359

3. Strazzullo P, Barba G, Cappuccio FP et al. (2001) Altered renal sodium handling in men with abdominal adiposity: a link to hypertension. J Hypertens 19:2157-2164

4. Cappuccio FP, Cook DG, Atkinson RW, Strazzullo P (1997) Prevalence, detection, and management of cardiovascular risk factors in different ethnic groups in south London. Heart 78:555-563

5. McKeigue PM (1996) Metabolic consequences of obesity and body fat pattern: lessons from migrant studies. Ciba Found Symp 201:54-64

6. Cappuccio FP, Cook DG, Atkinson RW, Wicks PD (1998) The Wandsworth Heart and Stroke Study. A populationbased survey of cardiovascular risk factors in different ethnic groups. Methods and baseline findings. Nutr Metab Cardiovasc Dis 8:371-385

7. Matthews DR, Hosker JP, Rudenski AS, Naylor BA, Treacher DF, Turner RC (1985) Homeostasis model assessment: insulin resistance and beta-cell function from fasting plasma glucose and insulin concentrations in man. Diabetologia 28:412-419

8. Expert Panel on Detection, Evaluation, and Treatment of High Blood Cholesterol in Adults (2001) Executive Summary of the Third Report of the National Cholesterol Education Program (NCEP) (Adult Treatment Panel III). JAMA 285:2486-2497

9. Cappuccio FP, Strazzullo P, Giorgione N et al. (1991) Renal tubular sodium handling and plasma atrial natriuretic peptide, renin activity and aldosterone in untreated men under normal living conditions. Eur J Clin Invest 21:40-46

10. Cappuccio FP, Strazzullo P (1993) Determinants of the renal clearance of exogenous lithium in a large sample of a white male working population. Clin Sci Lond 85:479-485

11. Sampson B (1991) Determination of low concentrations of lithium in biological samples using electrothermal absorption spectrometry. J Anal Atomic Spectrom 6:115-118

12. Folkerd E, Singer DR, Cappuccio FP, Markandu ND, Sampson B, MacGregor GA (1995) Clearance of endogenous lithium in humans: altered dietary salt intake and comparison with exogenous lithium clearance. Am J Physiol 268: F718-F722

13. Reaven GM (1995) Pathophysiology of insulin resistance in human disease. Physiol Rev 75:473-486

14. Zimmet P, Boyko EJ, Collier GR, de Courten M (1999) Etiology of the metabolic syndrome: potential role of insulin resistance, leptin resistance, and other players. Ann NY Acad Sci 892:25-44

15. Johnson D, Prud'homme D, Despres JP, Nadeau A, Tremblay A, Bouchard C (1992) Relation of abdominal obesity to hyperinsulinemia and high blood pressure in men. Int J Obes Relat Metab Disord 16:881-890
16. Marin P, Andersson B, Ottosson M et al. (1992) The morphology and metabolism of intraabdominal adipose tissue in men. Metabolism 41:1242-1248

17. Bonora E, Kiechl S, Willeit J et al. (1998) Prevalence of insulin resistance in metabolic disorders: the Bruneck Study. Diabetes 47:1643-1649

18. Ohlson LO, Larsson B, Svardsudd K et al. (1985) The influence of body fat distribution on the incidence of diabetes mellitus. 13.5 years of follow-up of the participants in the study of men born in 1913. Diabetes 34:1055-1058

19. Anonymous (1998) Clinical Guidelines on the Identification, Evaluation and Treatment of Overweight and Obesity in Adults-The Evidence Report. National Institutes of Health. Obes Res 6 [Suppl 2]: 51S-209S

20. Maaten JC ter, Voorburg A, Heine RJ, Wee PM ter, Donker AJ, Gans RO (1997) Renal handling of urate and sodium during acute physiological hyperinsulinaemia in healthy subjects. Clin Sci (Lond) 92:51-58

21. Rocchini AP (1994) The relationship of sodium sensitivity to insulin resistance. Am J Med Sci 307 [Suppl 1]:S75-S80

22. Maaten JC ter, Bakker SJ, Serne EH, Wee PM ter, Donker AJ, Gans RO (1999) Insulin's acute effects on glomerular filtration rate correlate with insulin sensitivity whereas insulin's acute effects on proximal tubular sodium reabsorption correlation with salt sensitivity in normal subjects. Nephrol Dial Transplant 14:2357-2363

23. Butlen D, Vadrot S, Roseau S, Morel F (1988) Insulin receptors along the rat nephron: [125I] insulin binding in microdissected glomeruli and tubules. Pflugers Arch 412:604-612

24. Skott P, Vaag A, Bruun NE et al. (1991) Effect of insulin on renal sodium handling in hyperinsulinaemic type 2 (non-insulin-dependent) diabetic patients with peripheral insulin resistance. Diabetologia 34:275-281

25. Baum M (1987) Insulin stimulates volume absorption in the rabbit proximal convoluted tubule. J Clin Invest 79:1104-1109

26. Takahashi N, Ito O, Abe K (1996) Tubular effects of insulin. Hypertens Res 19 [Suppl 1]:S41-S45

27. Blanchard RF, Davis PJ, Blas SD (1978) Physical characteristics of insulin receptors on renal cell membranes. Diabetes 27:88-95

28. Nakamura R, Hayashi M, Emmanouel DS, Katz AI (1986) Sites of insulin and glucagon metabolism in the rabbit nephron. Am J Physiol 250:F144-F150

29. Talor Z, Emmanouel DS, Katz AI (1982) Insulin binding and degradation by luminal and basolateral tubular membranes from rabbit kidney. J Clin Invest 69:1136-1146

30. Klisic J, Hu MC, Nief V et al. (2002) Insulin activates $\mathrm{Na}(+) / \mathrm{H}(+)$ exchanger 3: biphasic response and glucocorticoid dependence. Am J Physiol Renal Physiol 283:F532F539

31. Bankir L, Martin H, Dechaux M, Ahloulay M (1997) Plasma cAMP: a hepatorenal link influencing proximal reabsorption and renal hemodynamics? Kidney Int Suppl 59: S50-S56

32. Bankir L, Ahloulay M, Devreotes PN, Parent CA (2002) Extracellular cAMP inhibits proximal reabsorption: are plasma membrane cAMP receptors involved? Am J Physiol Renal Physiol 282:F376-F392

33. Kassab S, Kato T, Wilkins FC, Chen R, Hall JE, Granger JP (1995) Renal denervation attenuates the sodium retention and hypertension associated with obesity. Hypertension 25:893-897

34. Rocchini AP, Mao HZ, Babu K, Marker P, Rocchini AJ (1999) Clonidine prevents insulin resistance and hypertension in obese dogs. Hypertension 33:548-553 
35. Grassi G, Seravalle G, Dell'Oro R, Turri C, Bolla GB, Mancia G (2000) Adrenergic and reflex abnormalities in obesity-related hypertension. Hypertension 36:538-542

36. Bank N, Aynedjian HS (1990) Progressive increases in luminal glucose stimulate proximal sodium absorption in normal and diabetic rats. J Clin Invest 86:309-316

37. Hannedouche TP, Delgado AG, Gnionsahe DA, Boitard C, Lacour B, Grunfeld JP (1990) Renal hemodynamics and segmental tubular reabsorption in early type 1 diabetes. Kidney Int 37:1126-1133

38. Nosadini R, Sambataro M, Thomaseth K et al. (1993) Role of hyperglycemia and insulin resistance in determining sodium retention in non-insulin-dependent diabetes. Kidney Int 44:139-146

39. Sechi LA (1999) Mechanisms of insulin resistance in rat models of hypertension and their relationships with salt sensitivity. J Hypertens 17:1229-1237
40. Province MA, Arnett DK, Hunt SC et al. (2000) Association between the alpha-adducin gene and hypertension in the HyperGEN Study. Am J Hypertens 13:710-718

41. Strazzullo P, Iacone R, Siani A et al. (2001) Altered renal sodium handling and hypertension in men carrying the glucagon receptor gene (Gly40Ser) variant. J Mol Med 79:574-580

42. Dong YB, Zhu HD, Baker EH et al. (2001) T594M and G442V polymorphisms of the sodium channel beta subunit and hypertension in a black population. J Hum Hypertens $15: 425-430$

43. He FJ, Markandu ND, Sagnella GA, MacGregor GA (1998) Importance of the renin system in determining blood pressure fall with salt restriction in black and white hypertensives. Hypertension 32:820-824 